\title{
Presentation of Invasive Cervical Cancer in Bangladesh.
}

\author{
Jannatul Ferdous ${ }^{1}$, Shirin Akter Begum ${ }^{1}$, Noor-E-Ferdous ${ }^{2}$, Qamrun Nahar ${ }^{3}$, Sayeda Fatema Khatun ${ }^{3}$, Sabera \\ Khatun $^{4}$ \\ ${ }^{1}$ Associate Professor, ${ }^{2}$ Assistant Professor, ${ }^{3}$ Consultant, ${ }^{4}$ Professor, Gynaecologic Oncology wing, Department of Obstetrics and Gynaecology, \\ Bangabandhu Sheikh Mujib Medical University.
}

\begin{abstract}
:
Background: Cervical cancer is a disease of significant worldwide morbidity and mortality. More than $85 \%$ of the disease occurs in developing countries. Bangladesh, like other developing countries faces a burden of the disease. Objective: To find out the different way of presentation of invasive cervical cancer patients. Methods: This cross-sectional study was carried out in the Gynaecologic Oncology wing of the Department of Obstetrics and Gynaecology of Bangabandhu Sheikh Mujib Medical University (BSMMU) during $1^{\text {st }}$ January 2007 to $30^{\text {th }}$ April 2008. One hundred and four patients with invasive cervical cancer admitted in hospital were enrolled in the study by purposive sampling. All the information were collected in a pre-designed structured questionnaire. Data were analyzed using statistical program SPSS version: 17.0. Frequency distributions were used to present the characteristics of the patients. Chi-square test was calculated and the significant level was set at $\mathrm{P}<0.05$.Results: Maximum patients $(60.6 \%)$ were in stage II. Majority of the patients $(61.5 \%)$ presented with abnormal bleeding. Exophytic growth was found in the majority of the patients $(71.2 \%)$. Squamous cell carcinoma was more $(92.3 \%)$ in the majority of patients and adenocarcinoma was more in younger age group. Conclusion: The status of the patients in this study reflects advanced stage of the disease at presentation and the peak incidence was observed in 36-45 years age group.
\end{abstract}

Key words: Cervical cancer, Screening, Stage.

[BSMMUJ 2013; 6 (1) : 29-32]

\section{Introduction:}

Cervical cancer is a disease of significant worldwide morbidity and mortality. More than $85 \%$ of the global burden occurs in developing countries where it accounts for $13 \%$ of all female cancer ${ }^{1}$. There were about 530000 new cases of and 275000 deaths due to cervical cancer worldwide in $2008^{1}$. The burden of cervical cancer is disproportionately high in developing world ${ }^{2}$. Its contribution to cancer burden is significant across all cultures and economies. In the south east Asian region about half a million people die every year from cancer $^{3}$. Bangladesh like other developing countries faces a burden of the disease. Cervical cancer constitutes $20 \%-29 \%$ of the female cancer and $70 \%$ of all gynaecological malignancies in Bangladesh ${ }^{4}$. In Bangladesh, population based data

Address for Correspondence: Dr. Jannatul Ferdous Associate Professor, Gynaecologic Oncology, BSMMU

Mobile number: 0171160791,Email:jannatulferdous71@yahoo.com on gynaecological cancer is not available but according to the cancer registry report of National Institute of Cancer Research and Hospital in 2005-2007, cervical cancer is the second $(21.5 \%)$ leading cancer after breast cancer $(25.6 \%)$ in women ${ }^{5}$.Since cervical cancer is an important cause of disability and death of women in Bangladesh, this study was carried out to determine the various presentation of this disease.

\section{Methods:}

This cross sectional study was performed among the cervical cancer patients admitted in the Gynaecological Oncology wing of BSMMU during $1^{\text {st }}$ January 2007 to $30^{\text {th }}$ April 2008. The study included clinically diagnosed and microscopically verified cervical cancer patients. One hundred and four patients were included in the study by purposive sampling. The patients having any previous treatment were excluded from the study. An informed written consent was obtained from all the women before 
enrollment in the study. The information was collected in a pre-designed structured questionnaire by an interviewer. The questionnaire included the socio-demographic characteristics of the patients, age at diagnosis, parity, menopausal status, presenting complaints, stage of the disease at diagnosis, type of growth, histology and degree of differentiation. Staging was done according to International Federation of Gynaecology and Obstetrics (FIGO) classification. In cases where there were more than one presenting symptoms, the presentation assigned was the one that prompted the patient to seek medical advice. Data were rechecked, edited and analyzed using statistical program SPSS version: 17.0. Frequency distribution and cross tabulation were used to present the characteristics of the patients. Chi-square test was calculated and the significant level was set at $\mathrm{P}<0.05$.

\section{Results:}

A total of 104 cases of cancer cervix were recruited from the admitted patients in the Gynaecological oncology wing of BSMMU during one year four months period, from $1^{\text {st }}$ January 2007 to $30^{\text {th }}$ April 2008.Cancer cervix accounted for approximately $7.8 \%$ of all gynaecological patients and $70 \%$ of all gynaecological malignancies admitted in BSMMU in the year 2007.

Majority of the patients suffering from cervical cancer were of mean age of 45.21 years with $\mathrm{SD} \pm 9.75$ (range 26-80 years).More than $45 \%$ were within the age range of $36-45$ years [Figure-1]. Forty patients $(38.46 \%)$ in this study were postmenopausal and sixty-four $(61.54 \%)$ were premenopausal. About ninety-eight percent women were multiparous and only two patients $(1.9 \%)$ were primiparous. Seventeen $(16.3 \%)$ patients were in stage I, sixtythree $(60.6 \%)$ were in stage II and twenty $(19.2 \%)$ were in stage III. Two patients $(1.9 \%)$ could not be staged properly as they were discharged on risk bond [Table1].Maximum patients $(32.7 \%)$ were found to be in stage IIB at first detection and the least patients $(1.9 \%)$ were found in stage IV and there were no patient found in stage IA. Regarding presenting complaints, majority of the patients $(61.5 \%)$ presented with abnormal vaginal bleeding. Nineteen patients $(18.3 \%)$ presented with postmenopausal bleeding, twelve patients (11.5\%)presented with vaginal discharge and post coital bleeding occurred in six patients $(5.8 \%)$. Only one patient $(<1 \%)$ had abnormal pap smear report before the diagnosis of the disease[TableII].Regarding the type of growth , exophytic growth was found in the majority of the patients $(71.2 \%)$. The association between type of growth (gross appearance of cervix) and stage of the cancer is shown in TableIII. Exophytic growth was more in stage II Cancer and endophytic growth was more in stage III and stage IV cancer. The morphological categorization was squamous cell carcinoma in $92.3 \%$ cases and the rest was adenocarcinoma $(7.7 \%)$.The majority of patients $(39.4 \%)$ presented with moderately differentiated or grade II lesion and higher proportion of squamous cell carcinoma was found among 36-45 years of age group[Table-IV]. Moderately differentiated tumour were predominant variety in stage II $(47.6 \%)$, stage III $(30 \%)$ and stage IV $(100 \%)$ cancer respectively [Table-V]. Well differentiated tumour was predominant variety in stage I $(58.8 \%)$ cancer and this was statistically significant $(\mathrm{P}<0.05)$.

\section{Table-I}

Stage of cervical cancer at first detection

\begin{tabular}{lcc}
\hline Stage of Cervical Cancer & Frequency & Percentage \\
\hline I & 17 & $16.3 \%$ \\
II & 63 & $30.6 \%$ \\
III & 20 & $19.2 \%$ \\
IV & 2 & $1.9 \%$ \\
Not Staged & 2 & $1.9 \%$ \\
\hline Total & 104 & $100 \%$ \\
\hline \multicolumn{2}{c}{} \\
\end{tabular}

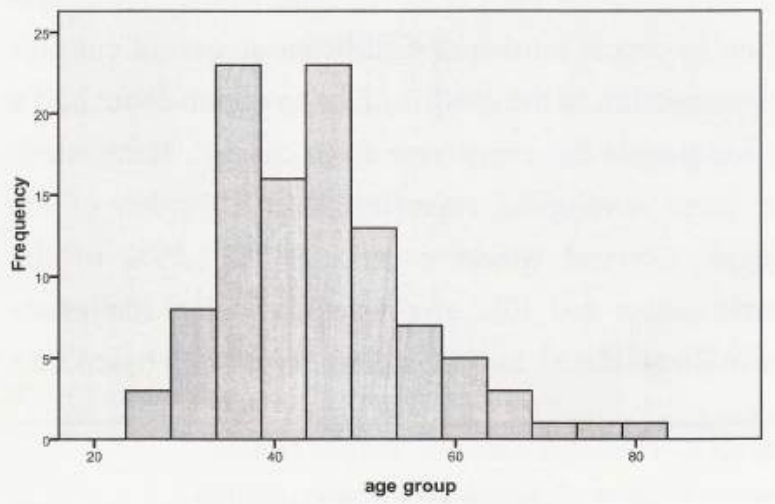

Fig-1: Frequency distribution in relation to age 
Table- II

Chief Complaint of the patients with cervical cancer $(n=104)$

\begin{tabular}{lcc}
\hline Chief complaint & Frequency & Percentage \\
\hline Abnormal vaginal bleeding & 64 & $61.5 \%$ \\
Postmenopausal bleeding & 19 & $18.3 \%$ \\
Vaginal discharge & 12 & $11.5 \%$ \\
Postcoital bleeding & 6 & $5.8 \%$ \\
Pain & 2 & $1.9 \%$ \\
Abnormal pap/VIA & 2 & $1.9 \%$ \\
\hline Total & 104 & $100.0 \%$ \\
\hline
\end{tabular}

Table-III

Association of type of growth with stage of disease $(n=104)$

Stage of cervical cancer

Type of growth

\begin{tabular}{lccccc}
\hline & Stage I & Stage II & Stage III & Stage IV & Not staged \\
\hline Exophytic & 14 & 47 & 11 & 1 & 1 \\
& $(82.4 \%)$ & $(74.6 \%)$ & $(55.0 \%)$ & $(50.0 \%)$ & $(50.0 \%)$ \\
Ulcerative & 3 & 13 & 1 & 0 & 1 \\
& $(17.6 \%)$ & $(19.0 \%)$ & $(5.0 \%)$ & $(0.0 \%)$ & $(50.0 \%)$ \\
Endophytic & 0 & 3 & 8 & 1 & 0 \\
& $(0.0 \%)$ & $(6.3 \%)$ & $(40.0 \%)$ & $(50.0 \%)$ & $(0.0 \%)$ \\
\hline Total & 17 & 63 & 20 & 2 & 2 \\
\hline
\end{tabular}

\section{Table-IV}

Association of Histopathological type with age group of patients $(n=104)$

Age group in yrs

Histopathology

\begin{tabular}{ccccc} 
& $<36$ & $36-45$ & $46-55$ & $>56$ \\
\hline Squamous cell & 16 & 42 & 24 & 14
\end{tabular}

carcinoma

\begin{tabular}{lcccc} 
Adenocarcinoma & 4 & 3 & 1 & 0 \\
\hline Total & 20 & 45 & 25 & 14 \\
\hline
\end{tabular}

Table-V

Association of stage of cancer with histologic grade

\begin{tabular}{lccc}
\hline Stage of cancer & \multicolumn{3}{c}{ Histologic grade } \\
\cline { 2 - 4 } & $\begin{array}{c}\text { Well } \\
\text { differentiated }\end{array}$ & $\begin{array}{c}\text { Moderately } \\
\text { differentiated }\end{array}$ & $\begin{array}{c}\text { Poorly } \\
\text { differentiated }\end{array}$ \\
\hline I & $10(58.8 \%)$ & $4(23.5 \%)$ & $3(17.6 \%)$ \\
II & $19(30.2 \%)$ & $30(47.6 \%)$ & $14(22.2 \$)$ \\
III & $8(21.6 \%)$ & $6(14.3 \%)$ & $6(24.0 \%)$ \\
IV & $0(0.0 \%)$ & $1(4.8 \%)$ & $1(0.8 \%)$ \\
Not staged & $0(0.0 \%)$ & $0(0.0 \%)$ & $2(1.9 \%)$ \\
\hline
\end{tabular}

Pearson Chi-Square test was done and the standardized statistic was $2.36 \mathrm{p}=0.004 \mathrm{df}=1$

\section{Discussion:}

Cervical cancer is rapidly becoming a major and growing public health hazard and cause of women's morbidity and mortality in our country. The age distribution of patients in this study was similar to that of the study done by Haghdel in Iran ${ }^{6}$. The peak incidence was in the fifth decade followed by an actual apparent decrease after 65.Another study found the rate of decline after age $60^{7}$.Patients were mainly multipara $(98.1 \%)$ and majority $(43.2 \%)$ were from grandmultiparity group. Some authors also found the incidence to increase from parity six onwards ${ }^{8}$.In this study only two patients $(1.9 \%)$ were primiparous and there was no nulliparous patient. Sobhan et al in their study also found $0.9 \%$ patient nulliparous in $\mathrm{NICRH}^{9}$. In contrast, a study done by Pretorius $\mathrm{R}$ et al showed that $18 \%$ of the patients were nulliparous ${ }^{10}$.The reason may be that the study was carried out in California,USA where premarital sexual exposure is more. In this study maximum patients $(60.6 \%)$ were found in stage II at first detection and no patient was found in stage IA, reflecting the lack of awareness of availability of cervical cancer screening in Bangladesh. The finding of this study are compatible with the study done by Sobhan in NICRH ${ }^{9}$.In the present study, exophytic growth was found in the majority $(71.2 \%)$ followed by ulcerative growth $(17.3 \%)$ and endophytic growth (11.5\%). The clinical stage of cervical cancer and the tumour size at the time of diagnosis are important prognostic factors of cervical cancer $^{11,12}$. The prognosis of the majority of the patients in this study is therefore likely to be poor as majority of patients are in advanced stages. Most common presenting complaint of the patients in this study was abnormal vaginal bleeding 
patients in this study was abnormal vaginal bleeding $(61.5 \%)$. This finding is similar to other study ${ }^{6,10}$. Report with abnormal pap smear was found in only one patient. In the study of Pretorius R et al, abnormal pap smear was the presentation in $28 \%$ cases $^{10}$. Comparing the two, the difference in presentation lies in the utilization of cervical cancer screening programmes. There has been a substantial decline in the incidence of and mortality from cervical cancer in the developed countries. In all populations, there is a direct relationship between the proportion of the population screened and declining incidence of cervical cancer and deaths from cervical cancer. Population-based screening programs have lead to $50-80 \%$ reduction in deaths from cervical cancer in various developed countries $^{13}$. In this study, no patient was found in stage IA. This is an important fact that despite of having no visible growth in cervix, a suspicious hypertrophic cervix might be harboring cancer. Many of such cases are initially undiagnosed but after surgery the histopathological report revealed cervical cancer. Hence, it is essential that all suspicious looking cervices should be subjected to colposcopy guided biopsy before undertaking definitive treatment. The morphological categorization of cervical cancer is also important. In this study the percentage of adenocarcinoma is $7.7 \%$ which is compatible with that of Lahore reports $(7.9 \%)^{14}$. There are disparate views on the significance of differentiation with regard to prognosis. Some authors have found that prognosis was more favorable in those with better differentiated tumours ${ }^{15}$.In this study maximum (39.4\%) patients had moderately differentiated tumour indicating poorer prognosis in those patients.

\section{Conclusion:}

The status of the patients of cervical cancer in BSMMU reflects late presentation of the disease and advanced stage of disease at presentation. Given the current socioeconomic status, it is unlikely that there will be an appreciable decline in the incidence of cervical cancer in Bangladesh in near future. Hence, the need is to educate the women about the symptoms of cervical cancer, cervical cancer screening and primary prevention of cervical cancer by HPV vaccination, so that the disease could be identified in a pre invasive or early stage and mortality and morbidity from cervical cancer could be reduced.

\section{References:}

1. Ferlay J, Shin HR, Bray F, Forman D, Mathers C and Parkin DM. GLOBOCAN 2008 V 1.2, Cancer Incidence and MortalityWorldwide: IARC Cancer Base No.10.Lyon,France:International Agency for Research on Cancer;2010.Available from:http//globocan.iarc.fr. accessed on 20/5/2012.

2. Parkin DM, Bray F, Chapter2: the burden HPV-related cancers. Vaccine 2006;24(suppl 3):S 11-25.

3. Stewart BW, Kleihues P.World cancer report, International Agency for Research on cancer, WHO, IARC press.2003; p-12.

4. Ferdous J, Khatun S, Hossain F,Parveen S, Nahar S . Epidemiopathological study of cancer cervix in Bangabandhu Sheikh Mujib Medical University.Bang.Onc.J.2009; 4(1):26-30.

5. Zaman MM, Baki MO.Cancer Registry Report, National Institute of Cancer Research and Hospital, WHO.2005-2007; p-19.

6. Haghdel M, Ardakany MS, Zeighami B.Invasive carcinoma of the uterine cervix in Iran.Int J Gynecol Obstet 1999; 64:265-71.

7. Devesa SS.Descriptive epidemiology of cancer of the uterine cervix.Obstet Gynecol 1984:63:605-12.

8. Emembolu JO, Ekkwempu CC.Carcinoma of the cervix uteri in Zaria: etiological factors.Int J Gynecol Obstet 1988; 26:265-69.

9. Sobhan F, Maula KJ.Presentation of Invasive Cervical Cancer..I Bangladesh Coll Phys Surg 2002; 20:115-19.

10. Pretorius R,Semrad N,Watring W,Fotheringham N.Presentation of Cervical Cancer.Gynecol Oncol 1991;42:48-53.

11. Pardanani NS,Tischler LP,Brown WH,Defeo E.Carcinoma of cervix.NY State J Med 1975;75:1018-21.

12. Gauthier P, Gore I .Shingleton HM, Soong SJ,Orr JWJR,Hatch KD.Identification of histopathologic risk groups in stage $\mathrm{Ib}$ squamous cell carcinoma of the cervix.Obstet Gynecol 1985;66:569-74

13. International Agency for Research on Cancer (2004) IARC Handbooks on Cancer Prevention. Volume 10.Cervix Cancer Screening. IARC Press: Lyon.

14. Badar F, Anwar N, Meerza F. Cervical carcinoma in a Muslim community. Asian Pac J cancer prev. 2007; 8:24-6.

15. Hurt WG, Silverberg SG, Frable WJ, Belgrad R, Crooks LD.Sr.Adenocarcinoma of the cervix: histopathologic and clinical features. Am J Obstet Gynecol 1977; 129:304-15. 